\title{
Fracture Energy Estimation of DCB Specimens Made of Glass/Epoxy: An Experimental Study
}

\author{
V. Alfred Franklin ${ }^{1}$ and T. Christopher ${ }^{2}$ \\ ${ }^{1}$ Faculty of Mechanical Engineering, Sardar Raja College of Engineering, Alangulam, Tirunelveli 627808, India \\ ${ }^{2}$ Faculty of Mechanical Engineering, Government College of Engineering, Tirunelveli 627007, India \\ Correspondence should be addressed to V. Alfred Franklin; frank_vin@yahoo.com
}

Received 22 May 2013; Accepted 20 June 2013

Academic Editor: Jacques Huot

Copyright (C) 2013 V. Alfred Franklin and T. Christopher. This is an open access article distributed under the Creative Commons Attribution License, which permits unrestricted use, distribution, and reproduction in any medium, provided the original work is properly cited.

\begin{abstract}
This paper examines critical load and corresponding displacement of double cantilever beam (DCB) composite specimens made of glass/epoxy of three different layups. Experiments were conducted on these laminates, and the fracture energy, $G_{\text {Ic }}$, was evaluated considering the root rotation at the crack tip. The present model requires the applied load-displacement history and crack extension to estimate fracture energy. Reduction schemes based on cubic and power law are also proposed to determine Young's modulus and energy release rate and found good agreement with the published and test results.
\end{abstract}

\section{Introduction}

The composites are heterogeneous materials, which are an important feature compared, for instance, to the metals and homogeneous plastics. The increasing use of composite materials in aircraft, spacecraft, automobile, and marine applications has motivated researchers to understand their fracture behaviour and damage mechanisms. General fracture processes in composite materials are complex. Fracture in composite materials is strongly dependent upon lamination order, ply-orientation, and constitutive relations. Failure can occur due to fiber-breakage, debonding of fibers, delamination, formation of matrix microcracks, and other microfailure modes. These defects may be as a result of residual stresses due to curing process, external impact damage, and environmental degradation or may develop in fabrication or service causing structural degradation at stresses well below the strength levels expected for defect-free material [1]. The interlaminar fracture also known as the delamination, which is one of the most important life-limiting failure modes, in laminated composite structures. The composite materials exhibit superior properties only along the fiber direction; hence the delamination of composite structures results in a significant loss of the strength and stiffness. As a result of this damage mechanism, the fracture characterization of composites structures acquires special relevancy [2].

Linear elastic fracture mechanics (LEFM) deals with the propagation of interlaminar cracks, by relating defect geometry and design stress to a material response, normally called fracture toughness, which is characterized by critical energy release rate. Different analytical approaches and specimen geometries have been used for calculating the modeI interlaminar fracture toughness [3-9]. For displacement controlled loading, DCB specimen gives rise to stable crack growth which makes it well suited for measurements of energy release rate, $G_{\text {Ic }}$. Thus the double cantilever beam specimen deserves strong consideration as a viable method for characterizing delamination growth induced by normal stress.

Evaluation of the mode-I fracture energy for a material relies heavily on the interpretation of fracture data which normally consist of a load-displacement $(P-\delta)$ record for specimens with cracks. For direct evaluation of, $G_{\text {Ic }}$ from the recorded fracture data, there are basically two different LEFM methods, namely, the "area" and "compliance" methods. Hashemi et al. [10] have used carbon/PEEK composite ("APC-2", ICI) and carbon/epoxy composite ("Fiberdux 6376C" Ciba Geigy) materials for determining the fracture 
energy through DCB specimens. They found a good agreement between values from the area and compliance methods, but there is poor agreement with those values obtained from the "load" and "displacement" methods based on simple beam theory [1]. To account for these discrepancies, they have considered several factors, for example, errors in the measurement of crack length and displacement, shear correction and large displacement correction, and noted that none of these possible errors was significant enough to eliminate the discrepancies and correct the analytical method. Another source of error in their simple beam analysis is the assumption that the beams are built-in cantilevers (i.e., the slope and deflection are zero at the crack tip of the DCB specimen) and expected to result in an error of the crack length. The correction for the crack length was obtained using the fracture data in the expression for compliance derived from the simple cantilever beam theory, through a least-square curve fit. With this correction, the values of $G_{\text {Ic }}$ obtained from different methods are found to be in good agreement with each other.

Shokrieh and Heidari-Rarani [11] investigated the influence of stacking sequence on mode-I delamination resistance ( $R$-curve) behaviour of $E$-glass/epoxy DCB specimens of stacking sequences; $\left[0_{12}^{\circ}\right]_{s},\left[\left(0^{\circ} / 90^{\circ}\right)_{3}\right]_{2 s}$ and $\left[0^{\circ} / 90^{\circ} / \pm 45^{\circ} / 90^{\circ} / 0^{\circ}\right]_{2 s}$ with two initial crack lengths are used with an initial delamination between $0^{\circ} / / 0^{\circ}$ interface. They concluded that (i) the initiation delamination toughness of multidirectional (MD) laminates are much lower than that of unidirectional (UD) one, (ii) the stacking sequence has no effect on the fiber bridging length in DCB specimens, and (iii) greater the $D_{c}\left(=D_{12}^{2} / D_{11} D_{22}\right)$ value of a laminate, the steady-state propagation toughness is higher. Lot of efforts has led to the establishment of standard test methods for mode-I delamination initiation for unidirectional composites, while laminates widely used in industrial applications are multidirectional. It was found that interlaminar fracture toughness without fiber bridging has a constant value during the crack propagation. However, if the fiber bridging occurs in the wake of delamination front, the strain energy release rate is no longer a constant value and rises with increasing the delamination length. Crack propagation behavior of a stick-slip type is more observed for the unidirectional DCB specimens than the multidirectional ones. On the other hands crack at multidirectional laminates grows in a more stable manner. The Initiation fracture toughness and steadystate toughness are independent of initial crack length for any multidirectional stacking sequence. Stacking sequence does not affect the fiber-bridging length of DCB specimens, whereas it has pronounced effect on the maximum load value in the load-displacement curves [11].

Delaminations that form in multiply laminated composite structures occur between plies of dissimilar orientation, and fiber bridging does not occur. Hence, fiber bridging is considered to be an artefact of the DCB test on unidirectional materials. Therefore, the generic significance of $G_{\text {Ic }}$ propagation values calculated beyond the end of the implanted insert is questionable [12], and an initiation value of $G_{\text {Ic }}$ measured from the implanted insert is preferred.
The aim of the present study is intended to estimate $G_{\mathrm{Ic}}$ for glass/epoxy laminates of different stacking sequences and to predict the interface strength of composite laminates under monotonic loading. An attempt was made to predict the fracture energy and Young's modulus of different composite materials system based on the proposed data reduction schemes.

\section{Energy Release Rate Computation in Double Cantilever Beam Specimens}

The dependence of $R$ curves on the geometry of DCB specimens was investigated by Tamuzs et al. [13] for unidirectional carbon/epoxy composite laminates and the peculiarities of $R$ curve obtained on traditional DCB specimens loaded by wedge forces and calculations to predict the resistance to crack propagation in specimens of different thickness was presented. They modified the beam theory to calculate the energy release rate in terms of $P-\delta$ record. Usually, the energy release rate in a DCB specimen is defined as

$$
G=-\frac{\partial \prod}{B \partial a}
$$

The potential energy of a linearly elastic system is equal to

$$
\prod=\frac{1}{2} \int_{v} \sigma_{i j} \varepsilon_{i j} d v-\int_{0}^{u} P(u) d u,
$$

where $\sigma_{i j}$ and $\varepsilon_{i j}$ are the stress and strain, $v$ is the volume, and $P(u)$ is the force applied, which is a function of displacement. The first term is an energy stored in the linearly elastic body, and the second one is the work produced by the applied external force. The displacement, $u$, is a full opening of the DCB specimen at the point, where $P$ is applied. The first term is also expressed through the force acting on the system

$$
\prod=\frac{1}{2} P u-\int_{0}^{u} P(u) d u .
$$

From (1) and (3), it follows that

$$
G=\frac{P^{2}}{2 B} \frac{\partial C}{\partial a},
$$

where the compliance $C$ is defined as

$$
C=\frac{\delta}{P} \text {. }
$$

The Irwin-Kies formula (4) is well-known and widely used. Since there is no assumptions about the type of the crack tip structure was made, (4) is general and should be valid for any bridging law and specimen shape. But the energy release rate obtained can be functions of the specimen shape, is a characteristics of the material. Neglecting the bridging effect, the deflection of an ideal cantilever beam, (the full opening of the DCB equals the doubled deflection) is given by

$$
\delta=\frac{2 a^{3} P}{3 E I},
$$

and the compliance is

$$
C=\frac{2 a^{3}}{3 E I}
$$




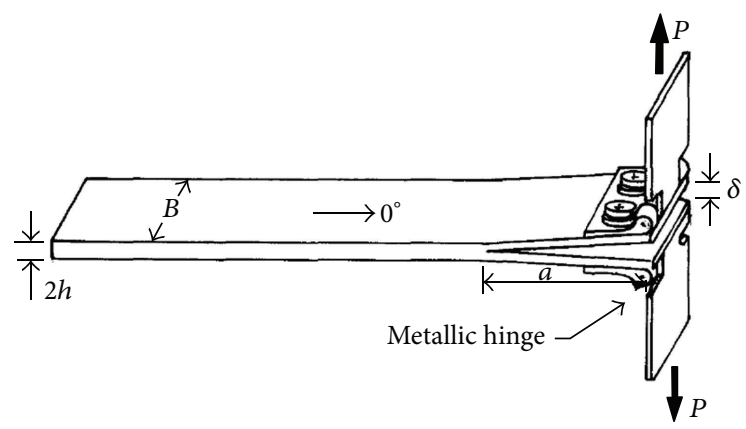

(a)

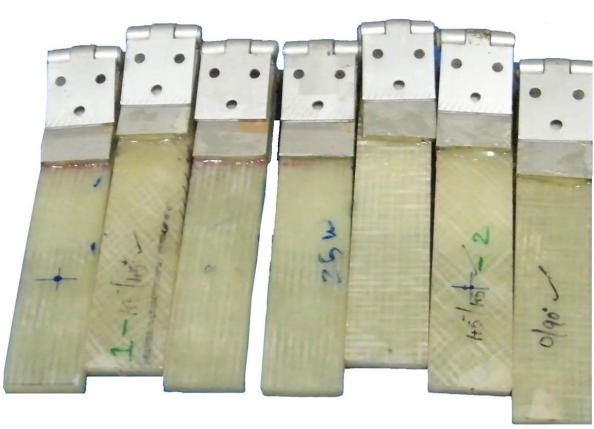

(b)

FIGURE 1: (a) Scheme of unidirectional DCB specimen for mode-I test. (b) DCB specimen of different layups made of glass/epoxy.

2.1. Evaluation of Mode-I Fracture Toughness. The critical strain energy release rate $\left(G_{\mathrm{Ic}}\right)$ from the fracture data of the double cantilever beam specimen (see Figure 1) can be evaluated from (4). $14]$

The compliance $(C)$ of the DCB specimen is given by $[1$,

$$
C=\frac{\delta}{P}=\frac{2}{3} \frac{a^{3}}{E I}+\frac{2}{K} a^{2} .
$$

Using (8) in (4), one can obtain

$$
G_{\mathrm{Ic}}=\frac{P_{\mathrm{cr}}^{2} a^{2}}{B E I}+\frac{2 P_{\mathrm{cr}}^{2} a}{B K} .
$$

Using (8) and eliminating $K$, one can write the following relation for $G_{\mathrm{Ic}}$ :

$$
G_{\mathrm{Ic}}=\frac{P_{\mathrm{cr}}^{2} a^{2}}{3 B E I}+\frac{P_{\mathrm{cr}} \delta_{\mathrm{cr}}}{B a}
$$

Here $P_{c r}$ is the critical load or load at the onset of the delamination. To minimize the scatter in measurements, the critical strain energy release rate $\left(G_{\mathrm{Ic}}\right)$ is evaluated from the fracture data of composite DCB specimens from

$$
G_{\mathrm{Ic}}=\frac{1}{N} \sum_{i=1}^{N}\left(\frac{P_{\mathrm{cr}}^{2} a^{2}}{3 B E I}+\frac{P_{\mathrm{cr}} \delta_{\mathrm{cr}}}{B a}\right)_{i}
$$

Here $N$ is the number of fracture data. The critical load $\left(P_{\mathrm{cr}}\right)$ is evaluated from

$$
P_{\mathrm{cr}}=\sqrt{G_{\mathrm{Ic}}\left\{\frac{a^{2}}{B E I}+\frac{2 a}{B K}\right\}^{-1}} .
$$

The rotational spring constant $(K)$ in $(12)$ is obtained from the fracture data as

$$
\frac{1}{K}=\left\{\sum_{i=1}^{N}\left(\frac{\delta_{\mathrm{cr}}}{P_{\mathrm{cr}}}-\frac{2}{3} \frac{a^{3}}{E I}\right)_{i} a_{i}^{2}\right\}\left\{\sum_{i=1}^{N} 2 a_{i}^{4}\right\}^{-1} .
$$

\subsection{Experimental Data Reduction Methods}

2.2.1. Cubic Polynomial Reduction. In this reduction scheme, the compliance polynomial is assumed as cubic equation and can be written in the form

$$
C=A_{1} a^{3}+A_{2} a^{2}+A_{3} a+A_{4} .
$$

Since the compliance equation (8) has cubic and quadratic terms alone, one can modify (14) as

$$
C=A_{1} a^{3}+A_{2} a^{2} .
$$

Comparing (15) with (8), the coefficients $A_{1}, A_{2}$ can be obtained as $A_{1}=2 / 3 E I$ and $A_{2}=2 / K$. By plotting compliance $(C)$ versus crack length $(a)$ curve, one can get the coefficients $A_{1}$ and $A_{2}$ for the particular specimen. From these coefficients the values of Young's modulus $(E)$ and rotational stiffness $(K)$ can be obtained for the particular specimen. This approach makes the calculation of rotational stiffness easier, and no separate test is required for the determination of young's modulus.

2.2.2. Power Law Reduction. Here the compliance polynomial is assumed to follow a power law in the form

$$
C=A_{1} a^{m} \text {. }
$$

Here also the coefficients $A_{1}$ and $m$ for the particular specimen can be obtained from the compliance $(C)$ versus crack length (a) curve. Here, $A_{1}=2 / 3 E I$. The value of $K$, may not be calculated in this method. By substituting (15) and (16) in Irwin-Kies equation (4), one can get the energy release rate of DCB specimens in a much simpler way.

\section{Experimental Work}

3.1. Materials and Specimen Preparation. The double cantilever beam (DCB) test is the most commonly used delamination test used for interlaminar fracture characterization under mode-I loading and has been standardized by the ASTM [12]. The specimens used for the present study consist of different three layups, namely, unidirectional $\left[0^{\circ}\right]_{6}$, angle ply $\left[ \pm 45^{\circ}\right]_{3}$, and cross ply $\left[0^{\circ} / 90^{\circ}\right]_{3}$ laminates made of $E$ glass/epoxy. The Reinforcing phase used is unidirectional 
glass fiber of 750 grams per square meter. The matrix phase is epoxy resin LY 556 with hardener HY951 in the ratio of $10: 1$ to promote or control the curing action and also to control the degree of hardness of the cured film. The initial crack was made by introducing a thin Teflon film of thickness $13 \mu \mathrm{m}$ during stacking procedure. Initially the upper and lower mould surfaces are cleaned using acetone to remove the dirt present. Once the dirt is being removed, wax is applied on both the surfaces. Mylar sheets were used to get better surface finish and ease in releasing the plate. The laminates contain six laminas to have the Teflon insert at the centre. The laminates were prepared by hand layup process. The excess resin present is squeezed by using rollers. The laminate is allowed to cure in the mould for about 7 days at room temperature.

As per ASTM standard (D5528), the optimum length of the DCB specimen should be at least $125 \mathrm{~mm}$, the width of the specimen should be around 20 to $25 \mathrm{~mm}$, and the thickness can be between $3-5 \mathrm{~mm}$. But if the material is too brittle, then there is possibility for breaking, and if it is too ductile, then the crosshead displacement will be high. But both these possibilities are not preferred. For materials with low-flexural modulus or high interlaminar fracture toughness, it may be necessary to increase the number of plies, that is, increase the laminate thickness or decreasing the delamination length in order to avoid large deflections of the specimen arms. Hence, the specimen thickness $(2 h)$ and initial delamination length $\left(a_{o}\right)$ shall be designed to satisfy the following criteria [15]:

$$
\begin{gathered}
a_{o} \leq 0.042 \sqrt{\frac{E_{11}(2 h)^{3}}{G_{\mathrm{Ic}}}}, \\
2 h \geq 8.48 \sqrt[3]{\frac{G_{\mathrm{Ic}} a_{o}^{2}}{E_{11}}} .
\end{gathered}
$$

The dimension of test specimen used here is $130 \times 25 \times 2 h$, and exact width of specimen was obtained by using water jet cutting. The specimen surfaces are scrubbed with sand paper and are cleaned thoroughly with acetone to remove dirt. For better bonding, the base of aluminium piano hinge is also scratched with file and is cleaned with acetone. A thin layer of araldite adhesive is used to fix the piano hinge to the specimen. Care should be taken that the araldite applied does not cover the sides of Teflon insert. Piano hinge is meant for applying load and to avoid moment at the loading point, so that the load is always perpendicular to the face of specimen. The maximum load anticipated during a DCB test of a material with a known modulus, $E_{11}$, and anticipated value of $G_{\text {Ic }}$ may be estimated by [15]

$$
P_{\max }=\frac{B}{a} \sqrt{\frac{G_{\mathrm{Ic}}(2 h)^{3} E_{11}}{96}} .
$$

3.2. Test Procedure. The specimens (see Figure 1(b)) were tested on Instron 3367 universal testing machine equipped with a $30 \mathrm{kN}$ load cell (see Figure 2) at room temperature. They were subjected to a wedge loading under displacement control. The cross head speed was set at $1 \mathrm{~mm} / \mathrm{min}$ to ensure

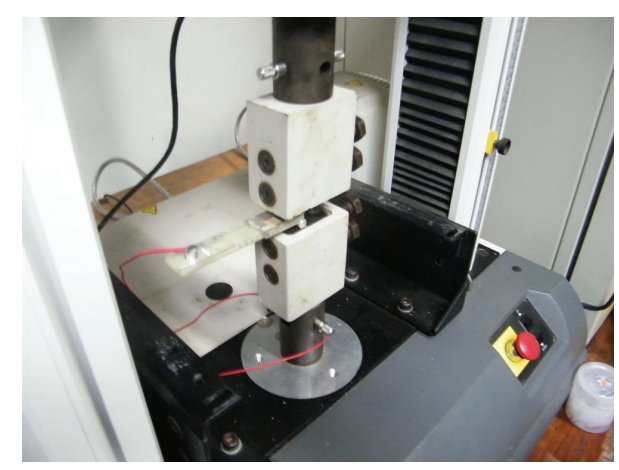

FIgURE 2: INSTRON 3367 universal testing machine.

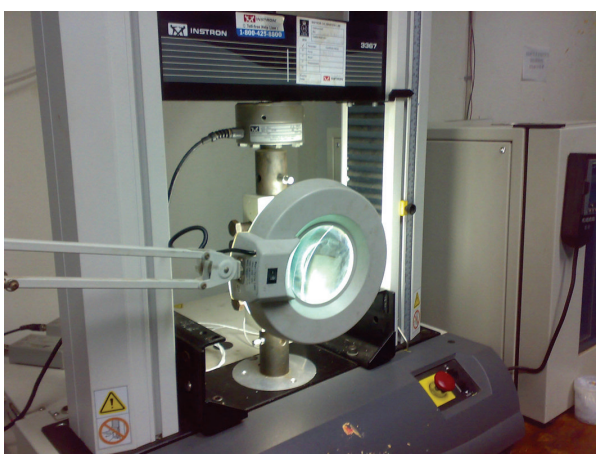

FIGURE 3: Magnifying lens for tracking crack.

steady crack propagation and ease of recording. The loaddisplacement $(P-\delta)$ history was recorded by the machine.

Markings were made on the specimen on both sides starting from the end of the insert as per ASTM standards. First five markings are made in an interval of $1 \mathrm{~mm}$, and the following four markings are made in an interval of $5 \mathrm{~mm}$. A magnifying lens (see Figure 3) or a travelling microscope was used to track the crack propagation. The crack growth from the starter insert was determined by careful inspection of the specimen edge by magnification lens and by observation of $P-\delta$ curve.

\section{Results and Discussions}

Fracture analysis has been carried out on the double cantilever beam specimens made of glass/epoxy of three different layups, namely, $\left[0^{\circ}\right]_{6},\left[ \pm 45^{\circ}\right]_{3}$ and $\left[0^{\circ} / 90^{\circ}\right]_{3}$, with midplane delamination. From Table 1 to Table 3, it has been observed that the fracture toughness of $\left[0^{\circ}\right]_{6}$ is higher than $\left[ \pm 45^{\circ}\right]_{3}$ and $\left[0^{\circ} / 90^{\circ}\right]_{3}$ specimens. The reason is that the $\left[0^{\circ}\right]_{6}$ laminate exhibited more fiber bridging during propagation than other two layups. Fiber bridging causes a large $G_{I c}$ value which overestimates the real mode-I fracture toughness [16]. Also it is observed that the failure of cross-ply laminate occurs at a smaller crack growth increment of $1 \mathrm{~mm}$; this may be due to the lack of fiber bridging and transverse matrix cracking of $90^{\circ}$ ply.

The critical load and the corresponding displacements obtained from experiments are closer to the present analysis. 
TABLE 1: Critical load, $P_{\mathrm{cr}}$, and corresponding displacement, $\delta_{\mathrm{cr}}$, for the measured crack length of a DCB specimen made of unidirectional glass/epoxy composite.

\begin{tabular}{|c|c|c|c|c|c|c|c|}
\hline \multicolumn{3}{|c|}{ Test results } & \multicolumn{5}{|c|}{ Present analysis } \\
\hline \multirow[t]{2}{*}{ Crack length, $a(\mathrm{~mm})$} & \multirow{2}{*}{$P(\mathrm{~N})$} & \multirow[t]{2}{*}{$\delta(\mathrm{mm})$} & \multirow{2}{*}{$P_{\text {cr }}(\mathrm{N})(12)$} & \multirow{2}{*}{$\delta_{\mathrm{cr}}(\mathrm{mm})(8)$} & \multicolumn{2}{|c|}{$\%$ Relative error in } & \multirow{2}{*}{$P_{\max },(18)$} \\
\hline & & & & & Load & Displacement & \\
\hline 44 & 127.77 & 6.22 & 138.15 & 6.47 & -8.13 & -4.11 & 161.77 \\
\hline 45 & 125.89 & 6.33 & 135.49 & 6.74 & -7.63 & -6.37 & 158.18 \\
\hline 46 & 125.41 & 6.68 & 132.93 & 7.01 & -6.00 & -4.88 & 154.74 \\
\hline 47 & 123.16 & 6.94 & 130.46 & 7.28 & -5.93 & -4.92 & 151.45 \\
\hline 48 & 121.15 & 7.21 & 128.09 & 7.56 & -5.73 & -4.83 & 148.29 \\
\hline 53 & 118.99 & 9.19 & 117.42 & 9.03 & 1.32 & 1.69 & 134.30 \\
\hline 58 & 117.13 & 11.48 & 108.41 & 10.63 & 7.45 & 7.40 & 122.72 \\
\hline 63 & 108.78 & 13.29 & 100.68 & 12.36 & 7.45 & 7.05 & 112.98 \\
\hline 68 & 104.84 & 15.73 & 93.99 & 14.21 & 10.34 & 9.66 & 104.68 \\
\hline
\end{tabular}

Layup: $[0]_{6}, B=25 \mathrm{~mm}, 2 h=5.86 \mathrm{~mm}, a_{o}=43 \mathrm{~mm}, E=36 \mathrm{GPa}, K=231 \mathrm{Nm}$, and $G_{\mathrm{Ic}}=1075 \mathrm{~J} / \mathrm{m}^{2}$.

TABle 2: Critical load, $P_{\text {cr }}$, and corresponding displacement, $\delta_{\mathrm{cr}}$, for the measured crack length of a DCB specimen made of angle ply glass/epoxy composite.

\begin{tabular}{|c|c|c|c|c|c|c|c|}
\hline \multicolumn{3}{|c|}{ Test results } & \multicolumn{5}{|c|}{ Present analysis } \\
\hline \multirow[t]{2}{*}{ Crack length, $a(\mathrm{~mm})$} & \multirow[t]{2}{*}{$P(\mathrm{~N})$} & \multirow[t]{2}{*}{$\delta(\mathrm{mm})$} & \multirow[t]{2}{*}{$P_{\mathrm{cr}}(\mathrm{N})(12)$} & \multirow[t]{2}{*}{$\delta_{\mathrm{cr}}(\mathrm{mm})(8)$} & \multicolumn{2}{|c|}{$\%$ Relative error in } & \multirow{2}{*}{$P_{\max },(18)$} \\
\hline & & & & & Load & Displacement & \\
\hline 47 & 74.56 & 5.89 & 73.13 & 5.80 & 1.92 & 1.54 & 73.13 \\
\hline 48 & 73.84 & 6.31 & 71.60 & 6.05 & 3.03 & 4.15 & 71.60 \\
\hline 49 & 71.18 & 6.55 & 70.14 & 6.30 & 1.46 & 3.69 & 70.14 \\
\hline 50 & 68.18 & 6.68 & 68.74 & 6.56 & -0.82 & 1.75 & 68.74 \\
\hline 51 & 64.42 & 7.01 & 67.39 & 6.83 & -4.61 & 2.56 & 67.39 \\
\hline 56 & 59.72 & 8.09 & 61.37 & 8.24 & -2.77 & -1.75 & 61.37 \\
\hline 61 & 58.76 & 10.07 & 56.34 & 9.77 & 4.11 & 2.91 & 56.34 \\
\hline 66 & 51.56 & 11.61 & 52.08 & 11.44 & -1.00 & 1.42 & 52.08 \\
\hline 71 & 49.01 & 12.83 & 48.41 & 13.24 & 1.24 & -3.23 & 48.41 \\
\hline
\end{tabular}

Layup: $[ \pm 45]_{3}, B=25 \mathrm{~mm}, 2 h=6.36 \mathrm{~mm}, a_{o}=46 \mathrm{~mm}, E=12.9 \mathrm{GPa}, 1 / K \rightarrow 0$, and $G_{\mathrm{Ic}}=543 \mathrm{~J} / \mathrm{m}^{2}$.

TABle 3: Critical load, $P_{\mathrm{cr}}$, and corresponding displacement, $\delta_{\mathrm{cr}}$, for the measured crack length of a DCB specimen made of cross-ply glass/epoxy composite.

\begin{tabular}{|c|c|c|c|c|c|c|c|}
\hline \multicolumn{3}{|c|}{ Test results } & \multicolumn{5}{|c|}{ Present analysis } \\
\hline \multirow{2}{*}{ Crack length, $a(\mathrm{~mm})$} & \multirow{2}{*}{$P(\mathrm{~N})$} & \multirow{2}{*}{$\delta(\mathrm{mm})$} & \multirow{2}{*}{$P_{\mathrm{cr}}(\mathrm{N})(12)$} & \multirow{2}{*}{$\delta_{\mathrm{cr}}(\mathrm{mm})(8)$} & \multicolumn{2}{|c|}{$\%$ Relative error in } & \multirow{2}{*}{$P_{\max },(18)$} \\
\hline & & & & & Load & Displacement & \\
\hline 48 & 72.27 & 6.46 & 74.11 & 8.13 & -2.54 & -25.97 & 77.32 \\
\hline 49 & 72.11 & 7.03 & 72.66 & 8.46 & -0.75 & -20.45 & 75.74 \\
\hline 50 & 71.89 & 7.58 & 71.26 & 8.80 & 0.88 & -16.08 & 74.23 \\
\hline 51 & 69.89 & 8.23 & 69.92 & 9.14 & -0.03 & -11.10 & 72.77 \\
\hline 52 & 68.55 & 8.65 & 68.62 & 9.49 & -0.11 & -9.76 & 71.37 \\
\hline 57 & 65.90 & 10.57 & 62.81 & 11.33 & 4.68 & -7.24 & 65.11 \\
\hline 62 & 61.93 & 16.47 & 57.91 & 13.34 & 6.49 & 19.03 & 59.86 \\
\hline 67 & 59.38 & 18.29 & 53.71 & 15.50 & 9.54 & 15.24 & 55.39 \\
\hline 72 & 51.65 & 19.89 & 50.09 & 17.83 & 3.03 & 10.35 & 51.55 \\
\hline
\end{tabular}

Layup: $[0 / 90]_{3}, B=25 \mathrm{~mm}, 2 h=6.16 \mathrm{~mm}, a_{o}=47 \mathrm{~mm}, K=327 \mathrm{Nm}$, and $G_{\mathrm{Ic}}=724 \mathrm{~J} / \mathrm{m}^{2}$.

The critical load obtained from the experiment is lower than the maximum anticipated load (18) in unidirectional specimen and is closer in other cases. If the rotational stiffness $K$ is very large, the effect of $K$ is not significant in that particular case. In angle ply laminate specimen, the value
$1 / K \rightarrow 0$ and hence the critical load obtained from the present analysis are equal to the maximum anticipated load as per ASTM standard (see Table 2).

Data reduction schemes, namely, cubic polynomial and power law to evaluate $G_{\mathrm{Ic}}$ and $E$ were presented in Table 4 . 
TABLE 4: Comparison of energy release rate and Young's modulus of unidirectional composites based on analytical data reduction schemes.

\begin{tabular}{|c|c|c|c|c|c|c|}
\hline \multirow{2}{*}{ Material } & \multicolumn{3}{|c|}{ Critical energy release rate, $G_{\mathrm{Ic}}\left(\mathrm{J} / \mathrm{m}^{2}\right)$} & \multicolumn{3}{|c|}{ Young's modulus, $E(\mathrm{GPa})$} \\
\hline & Strength of material approach (11) & Cubic law & Power law & Published result & Cubic law & Power law \\
\hline Carbon/PEEK [1] & 2006.37 & 2051.68 & 2149.03 & 130.0 & 129.94 & 136.06 \\
\hline Carbon/epoxy [1] & 262.73 & 261.60 & 287.90 & 136.0 & 135.60 & 139.65 \\
\hline Carbon/PES [17] & 2150.64 & 2121.76 & 2230.22 & 127.0 & 126.43 & 131.15 \\
\hline T300-634 DDS [19] & 642.13 & 641.01 & 641.80 & 133.0 & 132.53 & 133.06 \\
\hline Carbon/epoxy [20] & 364.07 & 361.60 & 428.94 & 150.0 & 135.99 & 137.41 \\
\hline CYCOM-982 [21] & 262.33 & 264.10 & 271.79 & 136.0 & 137.65 & 141.87 \\
\hline APC-2 [21] & 1563.81 & 1582.46 & 1655.85 & 129.0 & 130.75 & 133.56 \\
\hline Carbon/PEK-C [16] & 877.33 & 873.70 & 875.12 & 48.2 & 46.80 & 49.94 \\
\hline Carbon/BMI T300/QY8911 [18] & 170.60 & 196.09 & 214.54 & 135.0 & 133.46 & 141.12 \\
\hline Glass/BMI S2/QY8911 [18] & 1090.40 & 1098.87 & 1217.07 & 42.8 & 43.2 & 54.09 \\
\hline Glass/epoxy [14] & 1175.53 & 806.60 & 854.50 & 48.5 & 40.35 & 58.01 \\
\hline Glass/Polyester [22] & 1018.16 & 1018.11 & 1203.35 & 33.0 & 39.48 & 41.15 \\
\hline Glass/epoxy, $[0]_{6}$ Present test & 1075.00 & 1109.51 & 1098.48 & 36.0 & 33.5 & 38.6 \\
\hline
\end{tabular}

Test results of various material system for the comparison of present study were taken from [16] to [22]. These data reduction schemes show that the cubic polynomial compliance equation predicts closer $G_{\mathrm{Ic}}$ value with the test results than the power law assumption as the former includes the effect of rotational stiffness.

\section{Concluding Remarks}

The delamination analysis of laminated glass/epoxy DCB specimens of different layups was carried out, considering root rotation at the crack tip, and it was found that the $G_{\text {Ic }}$ value of unidirectional specimen is higher than other two layups because of extensive fiber bridging during crack propagation. Also it was observed that the effect of rotational stiffness on critical load is negligible if $K$ is too large.

Furthermore data reduction schemes were presented to determine Young's modulus $(E)$, rotational stiffness $(K)$, and energy release rate $\left(G_{\text {Ic }}\right)$ of specimens made of different material combinations with different layups, and a reasonable agreement was obtained with the published as well as test results. Hence, these data reduction schemes reduce the requirement of additional test to determine the modulus $E$.

\section{Nomenclature}

lla: Crack length

$B$ : Width of the DCB specimen

$C$ : Compliance of the specimen

DCB: Double cantilever beam

$E$ : Longitudinal tensile modulus

$G_{I}: \quad$ Strain energy release rate (SERR)

$G_{\mathrm{Ic}}$ : Fracture toughness or critical strain energy release rate

2h: Specimen thickness

I: $\quad$ Moment of Inertia

$K$ : $\quad$ Rotational spring stiffness

$N$ : Number of fracture data

$P$ : Applied Load on both sides of the specimen $\delta$ : Crack mouth opening displacement

$\Pi$ : Potential energy.

\section{References}

[1] B. Nageswara Rao and A. R. Acharya, "Evaluation of fracture energy, $G_{\text {Ic }}$ using a double cantilever beam fibre composite specimen," Engineering Fracture Mechanics, vol. 51, no. 2, pp. 317-322, 1995.

[2] M. F. S. F. de Moura, R. D. S. G. Campilho, A. M. Amaro, and P. N. B. Reis, "Interlaminar and intralaminar fracture characterization of composites under mode I loading," Composite Structures, vol. 92, no. 1, pp. 144-149, 2010.

[3] D. F. Devitt, R. A. Schapery, and W. L. Bradley, "A method for determining mode I delamination fracture toughness of elastic and viscoelastic composite materials," Journal of Composite Materials, vol. 14, pp. 270-285, 1980.

[4] J. M. Whitney, C. E. Browning, and W. Hoogsteden, "A double cantilever beam test for characterizing mode I delamination of composite materials," Journal of Reinforced Plastics and Composites, vol. 1, no. 4, pp. 297-313, 1982.

[5] R. A. Jurf and R. B. Pipes, "Interlaminar fracture of composite materials," Journal of Composite Materials, vol. 16, no. 5, pp. 386394, 1982.

[6] D. J. Nicholls and J. P. Gallagher, "Determination of $G_{\text {Ic }}$ in angleply composites using a cantilever beam test method," Journal of Reinforced Plastics and Composites, vol. 2, no. 1, pp. 2-17, 1983.

[7] P. E. Keary, L. B. Ilcewicz, C. Shaar, and J. Trostle, "Mode I interlaminar fracture toughness of composites using slender double cantilevered beam specimens," Journal of Composite Materials, vol. 19, no. 2, pp. 154-177, 1985.

[8] E. F. Rybicki, T. D. Hernandez Jr., J. E. Deibler, R. C. Knight, and S. S. Vinson, "Mode I and mixed mode energy release rate values for delamination of graphite/epoxy test specimens," Journal of Composite Materials, vol. 21, no. 2, pp. 105-123, 1987.

[9] J. G. Williams, "Large displacement and end block effects in the DCB interlaminar test in modes I and II," Journal of Composite Materials, vol. 21, no. 4, pp. 330-347, 1987. 
[10] S. Hashemi, A. J. Kinloch, and J. G. Williams, "Corrections needed in double-cantilever beam tests for assessing the interlaminar failure of fibre-composites," Journal of Materials Science Letters, vol. 8, no. 2, pp. 125-129, 1989.

[11] M. M. Shokrieh and M. Heidari-Rarani, "Effect of stacking sequence on R-curve behavior of glass/epoxy DCB laminates with $0^{\circ} / / 0^{\circ}$ crack interface," Materials Science and Engineering A, vol. 529, no. 1, pp. 265-269, 2011.

[12] ASTM Standard D5528-94a. Standard test method for mode I interlaminar fracture toughness of unidirectional continuous fiber reinforced polymer matrix composites, Philadelphia, $\mathrm{Pa}$, USA, 1994.

[13] V. Tamuzs, S. Tarasovs, and U. Vilks, "Progressive delamination and fiber bridging modeling in double cantilever beam composite specimens," Engineering Fracture Mechanics, vol. 68, no. 5, pp. 513-525, 2001.

[14] B. N. Rao and A. R. Acharya, "Maximum load at the initiation of delamination growth in a double cantilever beam specimen," Zeitschrift fuer Metallkunde, vol. 86, no. 6, pp. 428-433, 1995.

[15] R. A. Naik, J. H. Crews Jr, and K. N. Shivakumar, "Effects of Ttabs and large deflections in DCB specimen tests," in Composite Materials, Fatigue and Fracture, T. K. O’Brien, Ed., vol. 3 of ASTM STP 1110, pp. 169-186, American Society For Testing and Materials, 1991.

[16] J. Zhou, T. He, B. Li, W. Liu, and T. Chen, "A study of mode I delamination resistance of a thermoplastic composite," Composites Science and Technology, vol. 45, no. 2, pp. 173-179, 1992.

[17] S. Hashemi, A. J. Kinloch, and J. G. Williams, "Mechanics and mechanisms of delamination in a poly(ether sulphone)-Fibre composite," Composites Science and Technology, vol. 37, no. 4, pp. 429-462, 1990.

[18] L.-Y. Xu and C.-H. Kou, "Effect of interfacial interleaf to the interlaminar fracture and intralaminar fracture of a new BMI matrix composites system," Journal of Reinforced Plastics and Composites, vol. 13, no. 6, pp. 509-540, 1994.

[19] L. Ye, "Evaluation of Mode-I interlaminar fracture toughness for fiber-reinforced composite materials," Composites Science and Technology, vol. 43, no. 1, pp. 49-54, 1992.

[20] V. Q. Bui, E. Marechal, and H. Nguyen-Dang, "Imperfect interlaminar interfaces in laminated composites: delamination with the R-curve effect," Composites Science and Technology, vol. 60, no. 14, pp. 2619-2630, 2000.

[21] J. W. Gillespie Jr, L. A. Carlsson, R. B. Pipes, R. Rothschilds, B. Trethewey, and A. Smiley, "Delamination Growth in Composite Materials," NASA-CR 178066, 1986.

[22] A. Szekrényes and J. Uj, "Advanced beam model for fiberbridging in unidirectional composite double-cantilever beam specimens," Engineering Fracture Mechanics, vol. 72, no. 17, pp. 2686-2702, 2005. 

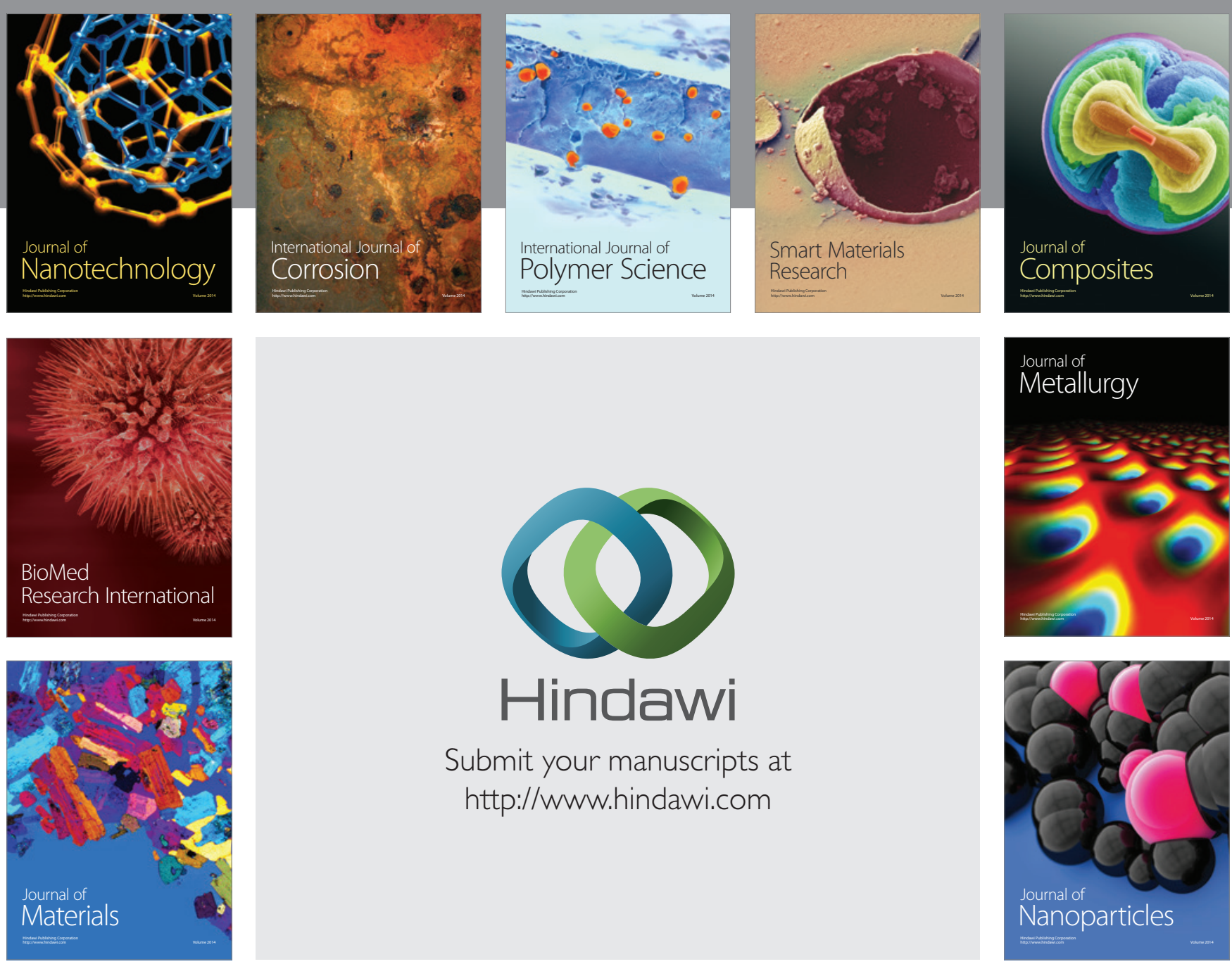

Submit your manuscripts at http://www.hindawi.com
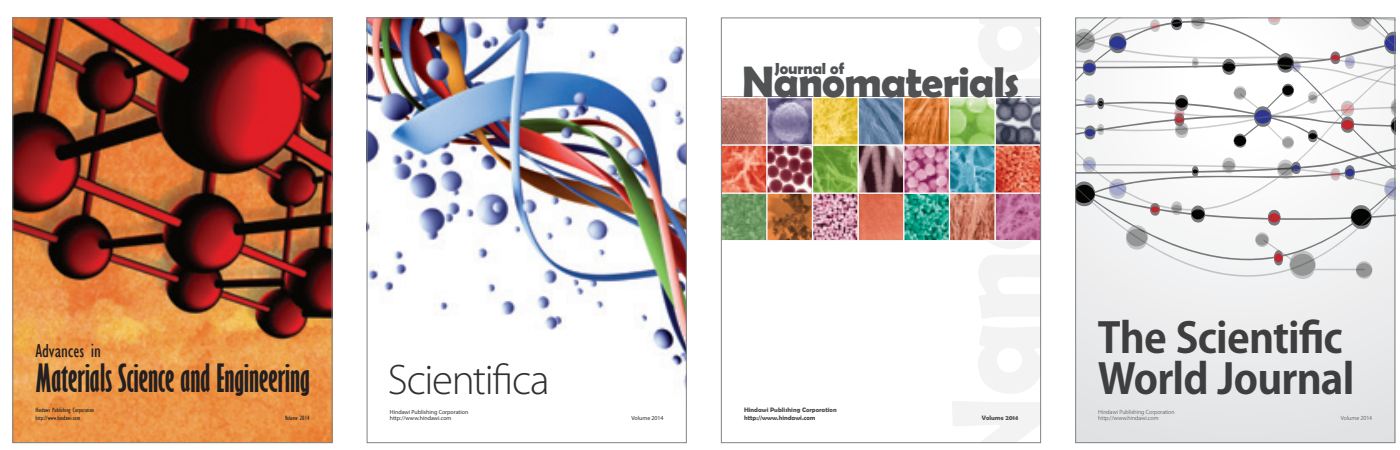

\section{The Scientific World Journal}
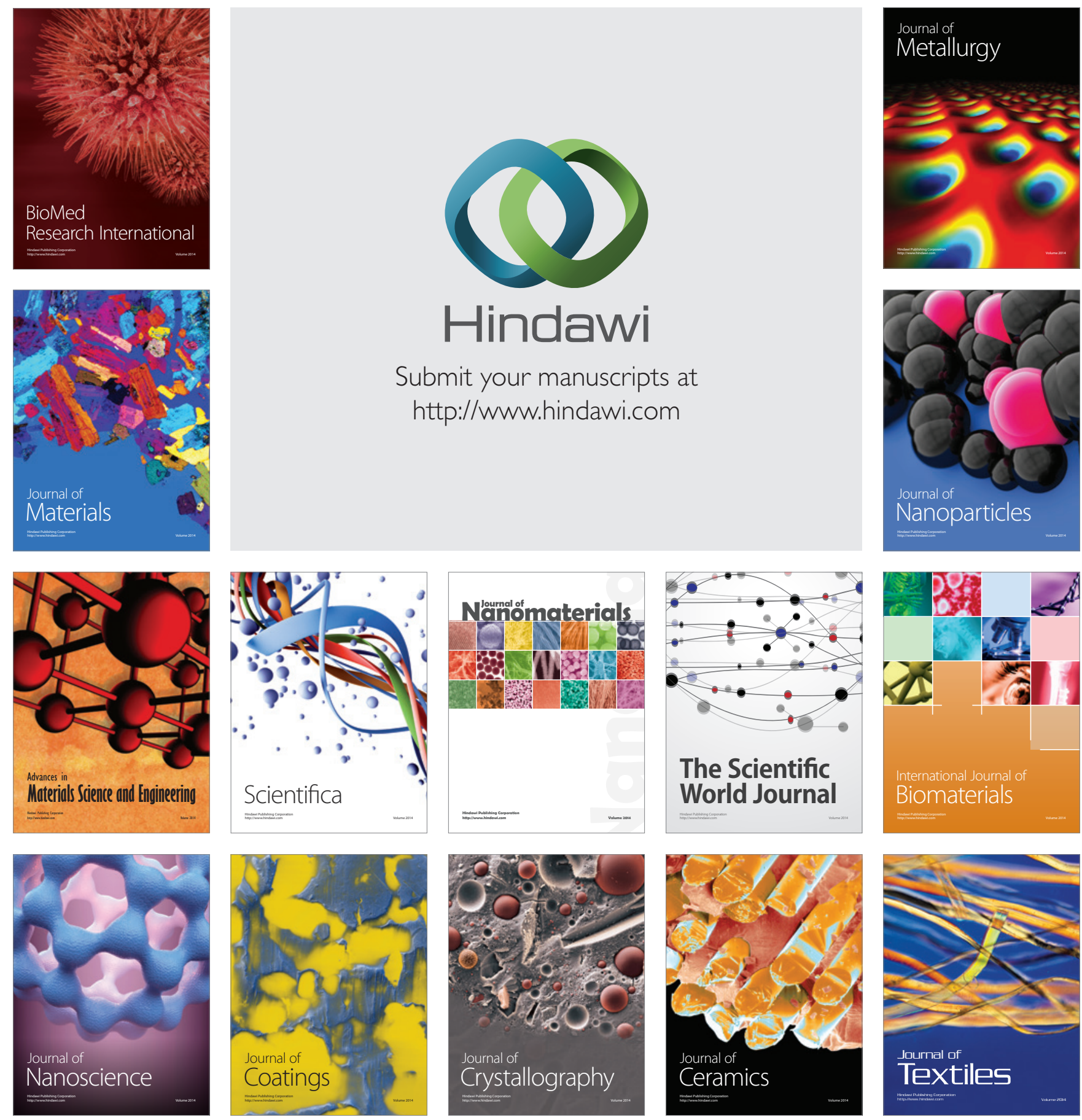